\section{Reported Death}

Hanna Y. Hanna, professor of horticulture at the Louisiana State University (LSU) AgCenter, age 73, passed away 28 July 2013.

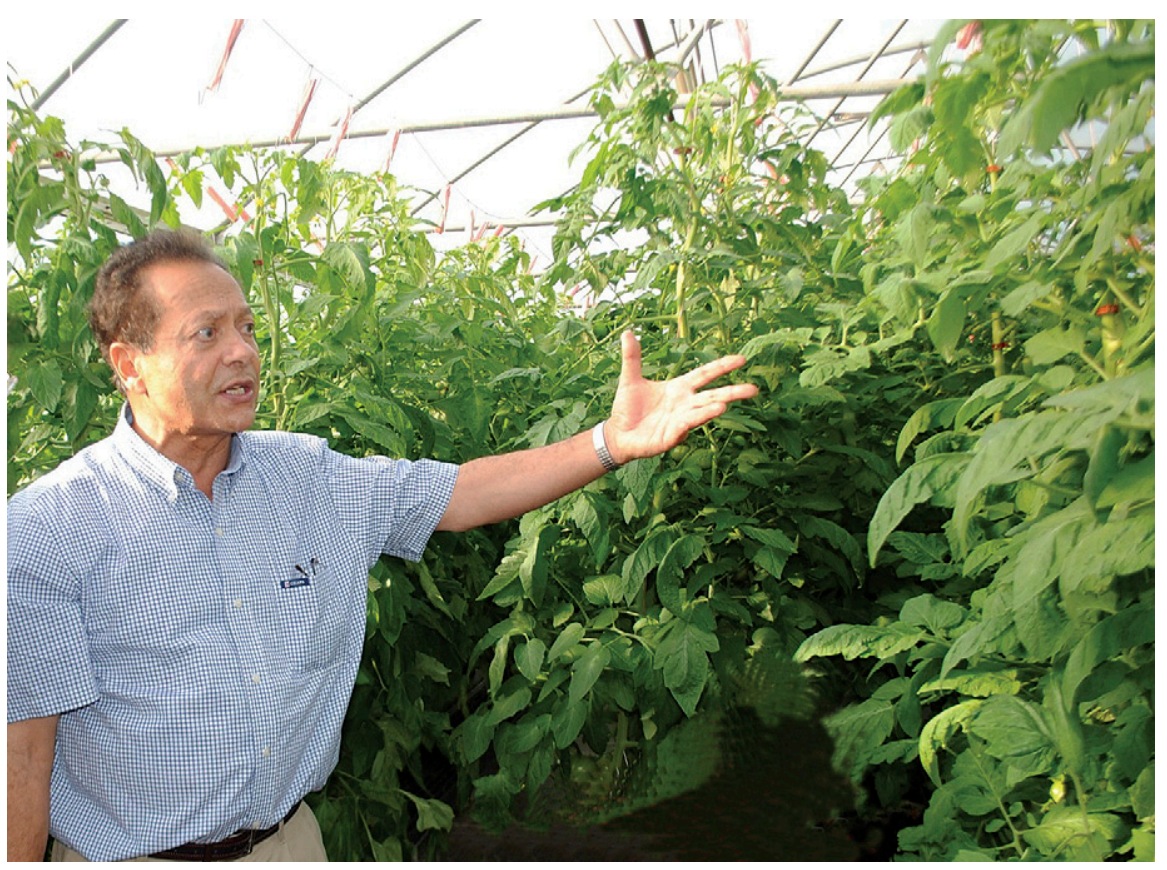

Hanna Y. Hanna
Dr. Hanna was a long-time member of the American Society for Horticultural Science and had served as a faculty member at the LSU AgCenter since 1981.

Hanna was awarded a BS degree in 1968 in extension agriculture and horticulture from Assiut University in Egypt and received a MS degree in horticulture from the same

university in 1972 . He moved to the United States in 1974 and completed a PhD in horticulture at LSU in 1980 and a master's degree in applied statistics in 1991. Hanna began his service as an LSU AgCenter horticulture faculty member in 1981 at the Citrus Research Station, Port Sulphur, LA. He later moved to the Red River Research Station, Bossier City, LA, where he served the past 21 years of his professional career.

A professor of vegetable crops, Hanna was well known regionally and nationally for his greenhouse tomato production research. He also conducted studies on cucumber, strawberries, peppers, field tomatoes, muskmelons, and other important vegetable crops in Louisiana.

Hanna was preceded in death by his wife of 44 years, Ansaf Hanna. He is survived by his son, Sherif Hanna, and his wife, Christine, and their two boys, Joshua and Luke; and his daughter, Sherin Mercer, and her husband, Matthew, and their two boys, Michael and Sam.

In memory of Dr. Hanna, memorials can be made to the Ann Hanna Transportation Fund at the Feist-Weiller Cancer Center in Shreveport, LA. Dr. Hanna will be remembered for his love of family, for his vegetable research, and for his faithful dedication to horticulture.

Allen D. Owings Professor (Horticulture) Hammond Research Station LSU AgCenter Hammond, LA 